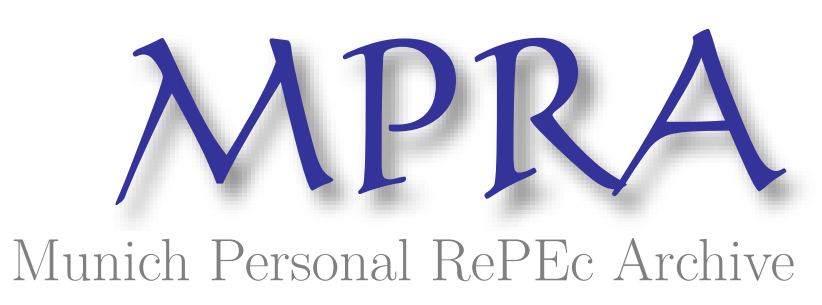

\title{
M of a kind: A Multivariate Approach at Pairs Trading
}

Perlin, M.

1 December 2007

Online at https://mpra.ub.uni-muenchen.de/8309/

MPRA Paper No. 8309, posted 17 Apr 2008 17:09 UTC 


\title{
M of a kind: A Multivariate Approach at Pairs Trading
}

\author{
Marcelo Scherer Perlin
}

ICMA/Reading University

\section{WORKING PAPER}

\author{
Version: December/2007
}




\title{
$M$ of a kind: A Multivariate Approach at Pairs Trading
}

\begin{abstract}
Pairs trading is a popular trading strategy that tries to take advantage of market inefficiencies in order to obtain profit. Such approach, on its classical formulation, uses information of only two stocks (a stock and its pairs) in the formation of the trading signals. The objective of this paper is to suggest a multivariate version of pairs trading, which will try to create an artificial pair for a particular stock based on the information of $m$ assets, instead of just one. The performance of three different versions of the multivariate approach was assessed for the Brazilian financial market using daily data from 2000 to 2006 for 57 assets. Considering realistic transaction costs, the analysis of performance was conducted with the calculation of raw and excessive returns, beta and alpha calculation, and the use of bootstrap methods for comparing performance indicators against portfolios build with random trading signals. The main conclusion of the paper is that the proposed version was able to beat the benchmark returns and random portfolios for the majority of the parameters. The performance is also found superior to the classic version of the strategy, Perlin (2006b). Another information derived from the research is that the proposed strategy picks up volatility from the data, that is, the annualized standard deviations of the returns are quite high. But, such event is "paid" by high positive returns at the long and short positions. This result is also supported by the positive annualized sharpe ratios presented by the strategy. Regarding systematic risk, the results showed that the proposed strategy does have a statistically significant beta, but it isn't high in value, meaning that the relationship between return and risk for the trading rules is still attractive.
\end{abstract}

\section{Introduction}

The market efficiency theory has been tested by different types of research. Such concept postulates, on its weak form, that the past trading information of a stock is reflected on its value, meaning that historical trading data has no potential for predicting future behavior of asset's prices. The main theorical consequence of this concept is that no logical rules of trading based on historical data should have a significant positive excessive return over some benchmark portfolio.

In opposition to the market efficiency theory, several papers have showed that past information is able, in some extent, to explain future stock market returns. Such predictability can appear in different ways, including time anomalies (day of the weak effect, French (1980)) and correlation between the asset's returns and others variables, Fama and French (1992). A substantial review on the market efficiency subject can be found at the papers of Fama (1991) and Dimson e Mussavian (1998).

A respectable amount of papers have tried to use quantitative tools in order to model the market and build trading rules. The basic idea of this type of research is to look for some kind of pattern in the historical stock price behavior and, using only historical information, take such pattern into account for the creation of long and short trading positions.

With the advent of computer power in the late 90's, more sophisticated mathematical methods could be employed in the case of trading rules. One example is the use of nearest neighbor algorithm in trading strategies, Fernandez-Rodrigues et al (2002), Fernandez-Rodrigues et al (1997), Fernandez-Rodrigues et al (2001) and Perlin (2006a). The NN algorithm is a non parametric method of modelling time series that has an intuitive appealing based on chaos theory. 
The main conclusion drawn from the results presented on the predictability potential of this method is that it is able to predict correct market direction for most of the forecasted financial observations. But its important to say that the evidence wasn't strong in all studies.

For the case of trading strategies based on parametric models, there is the work of Efetkhari (1997) on stock market and Dueker et al (2006) at currency. Both papers based the forecasts on the regime switching model, where the results indicated that the method can predict the financial time series researched in each case. Others types of strategies using quantitative formulations includes timing the market with fundamentals or statistical models, Brooks at al (2005) and Anderson et al (2006), momentum strategies, Siganos et al (2006) and Balsara et al (2006). The results from these papers are also positive.

A popular strategy that has made its reputation in the early 80's is the so called pairs trading. Such methodology was designed by a team of scientists from different areas (mathematics, computer sciences, physics, etc), which were brought together by the Wall Street quant Nunzio Tartaglia. The main objective of such team was to use statistical methods to develop computer based trading platforms, where the human subjectivity had no influence whatsoever in the process of making the decision of buy or sell a particular stock. Such systems were quite successful for a period of time, but the performance wasn't consistent after a while and the team was dismantled after a couple periods of bad performance. More details about the origins of pairs trading can be found at Vidyamurthy (2004) and Gatev et al (1999). The application of this particular strategy has already been conducted for financial time series. This includes the work of Nath (2003), Gatev et al (1999) and, more recently, Perlin (2006b).

The main objective of this research is to suggest a multivariate version of pairs trading. Such proposed approach will be executed to the data using three different weighting schemes. The profitability and the risk of such logical rules are going to be assessed based on the Brazilian financial market, with daily prices from 2000 to 2006. The present paper is based on the work of Perlin (2006b) and can naturally be seen as an extension of it since the methodologies used for performance assessment and the researched data is the same.

The paper is organized as follows; the first part is related to the explanation of the methodology of the research, including performance assessment and the logical rules of trading concerning pairs strategy. Second, the results from the execution of multivariate pairs trading over the researched database are presented. After that, the paper finishes with some concluding remarks.

\section{Methodology}

The methodology of this research is going to be divided in two parts: the first one is the formal definition of classical pairs trading and the suggested multivariate pairs trading. The second part introduces the method used for the calculation of raw and excessive returns. It should be pointed out that the pairs trading strategy can be implemented in many ways. In this particular research the methods chosen for execution of trading rules and performance assessment were selected according to its simplicity. 


\subsection{Classical Pairs Trading}

As said before, the idea of classical pairs trading is simple: find two stocks that move together and take long and short positions in the hope for the stocks' prices to move to the historical behavior. The first step is to normalize the price series of the assets. The reason for the unit transformation is straightforward; each stock has its own unit. After the normalization, all stocks are brought to the same standard unit and this permits a quantitatively fair formation of pairs.

The transformation employed is the normalization of the price series based on its mean and standard deviation, $P_{i t}^{*}=\frac{P_{i t}-E\left(P_{i t}\right)}{\sigma_{i}}$. The equation for the univariate pairs is presented next, Equation [1].

$P_{i t}^{*}=p_{i t}^{*}+\varepsilon_{i t}^{*}$

For Equation [1], the value of $P_{i t}^{*}$ is the normalized price series of asset $i$ at time $t$ and $p_{i t}^{*}$ is the normalized price of the pair of stock $i$, which is found by searching over the database using a "symmetry rule". For instance, the pair of stock $i$ can be identified using the squared distance rule, meaning that $p_{i t}^{*}$ is the asset in which the historical normalized price has, among all others, the lowest value of sum of squared error from $P_{i t}^{*}$. In another words, the asset $p_{i t}^{*}$ has the most symmetric behavior with $P_{i t}^{*}$.The term $\varepsilon_{i t}^{*}$ is just the residue from the difference, which, obviously, is in the same unit as $P_{i t}^{*}$ and $p_{i t}^{*}$.

After the pair of each stock is identified, the trading rule is going to create a trading signal at $t+1$ every time that the distance between $P_{i t}^{*}$ and $p_{i t}^{*}$ at time $t$ is higher than $d$. For instance, at a long position, this means that the stock is bought at the closing price at time $t$ and, if $d$ is uncrossed at $t+1$, then such assets is sold at the closing price of $t+1$, therefore gaining the return at time $t+1$. The value of $d$ is arbitrary, and it represents the filter for the creation of a trading signals. It can't be very high, otherwise only a few trading signal are going to be created and it can't be to low or the rule is going to be too flexible and it will result in too many trades and, consequently, high value of transaction costs.

After a trading sign is created, the next step is to define the positions taken on the stocks. According to the pairs trading strategy, if the value of $\varepsilon_{i t}^{*}$ is positive (negative) then a short (long) position is kept for asset $i$ and a long (short) position is made for the pair of asset $i$. The trading positions are closed when distance between $P_{i t}^{*}$ and $p_{i t}^{*}$ uncrosses $d^{l}$. Notes that there are two transactions here, the first for asset $i$ and the second for the pair of asset $i$. Such information is important when addressing transaction costs.

\footnotetext{
${ }^{1}$ This may sound counter intuitive, since, using continuous price behavior, if one buys when the distance is $\mathrm{d}$ and sells it when is the distance is again $\mathrm{d}$, there is no profit. But remember that the prices were in discrete time, meaning that the buying price occurs when the distance is higher (and not equal) than $\mathrm{d}$, therefore the expected profit is positive. For the case of pairs trading at approximate continuous time (eg. 5 min quotes), this can be easily adapted by setting a gap between the threshold for buying operation and for the sell operation
} 
The main logic behind the expected profits of classical pairs trading strategy is: if the movements between the pairs are going to continue in the future, then when the distance between an asset and its pair is higher than a particular threshold value $(d)$, there is a good possibility that such prices are going to converge in the future, and this can be explored for profit purposes. If the distance is positive, then the value of $P_{i t}^{*}$, according to the logic expressed earlier, probably will reduce in the future (short position for asset $i$ ) and the value of $p_{i t}^{*}$ is probably going to increase (long position for the pair of $i$ ). The same logic is true for the cases where the distance is negative.

As an example, Figure 1 shows the pairs trading strategy for weekly prices of asset TNLP4 and its pair, TNLP3. Notes that Figure 1 is the same as Figure 1 at Perlin (2006b).

Figure 1 - Example of Pairs Trading with TNLP4 and TNLP3 with $d=1$

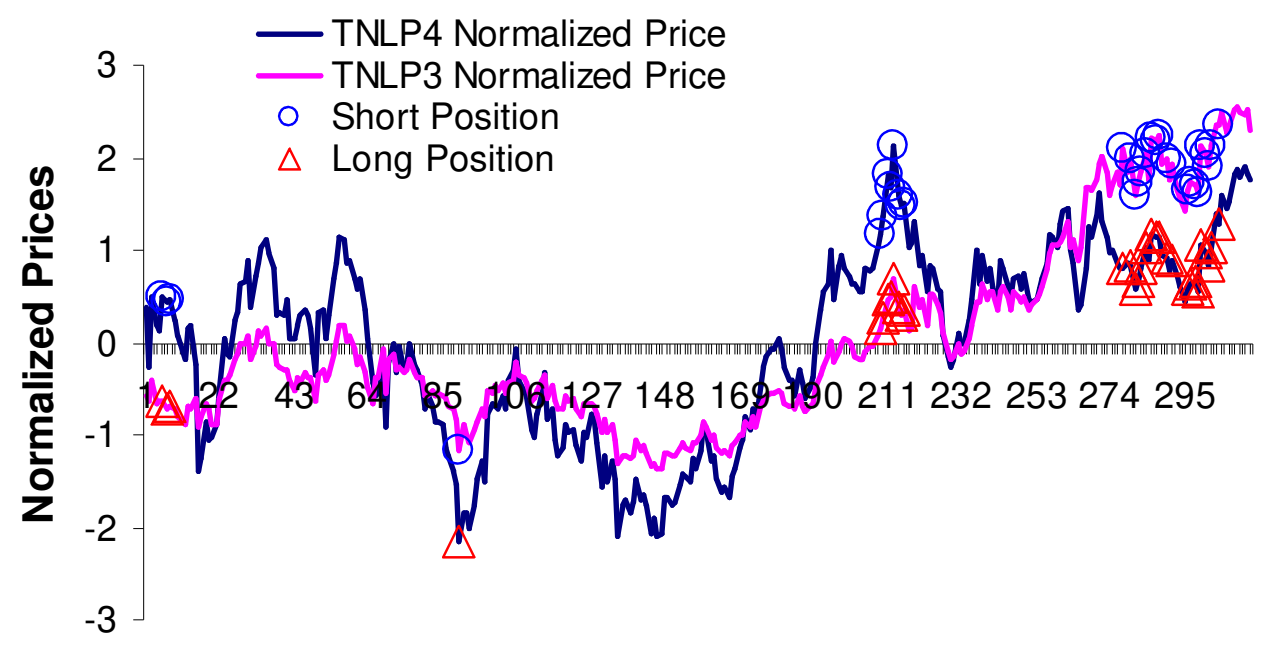

Time

In Figure 1, TNLP3 is the pair of TNLP4 based on the maximum correlation criteria ${ }^{2}$. It's possible to see that both normalized prices have a similar behavior. On the points that have a blue circle or red triangle the absolute difference in the normalized prices have crossed the value of $d$, meaning that a trade has taken place. The blue circles (red triangles) are the short (long) positions created. This happens every time the absolute distance is higher than 1 and the value of the analyzed asset is higher (lower) than it's pair. Every time the absolute difference uncrosses the value of $d$, the positions are closed. If the assets, after the opening of a position, move back to the historical relationship, then the one with the higher price should have a decrease in the prices and the one with the lower price should have an increase in price. Since a short position was made for the first asset and a long position for the second, then, if both prices revert to the historical behavior, a profit will arise from this trading case, and that's the whole idea behind pairs trading, making profits out of market reversions to the average behavior.

The situations where pairs trading fails to achieve profit are: a increase in the distance between $P_{i t}^{*}$ and $p_{i t}^{*}$, where the market goes the opposite way of the expectation and also a decrease

\footnotetext{
${ }^{2}$ One could also used the minimun squared distance rule.
} 
(increase) on the price of the long (short) position. Given that, one of the expectations in the use of classical pairs trading is that both stocks are behaving abnormally and this may not be true. It's possible that just one of them isn't behaving as expected, so the position taken on the other one may not be profitable. But how to know which one is badly priced and which one is not? One possible answer is to find others stocks that also present similar historical behavior with asset $i$ and check, for each time $t$, if the behavior of $i$ stands out when comparing to the others. This is the framework that motivates the proposed multivariate version of pairs trading, as will be explained next.

\subsection{Multivariate Version of Pairs Trading}

The idea behind this suggested multivariate version of pairs trading is to search a pair for asset $i$ not just with one asset, but with the information of $m$ assets. In other words, the basic approach is to build (and not just find) a pair to asset $i$. The formal explanation starts with the formula of the classical version, given next:

$P_{i t}^{*}=p_{i t}^{*}+\varepsilon_{i t}^{*}$

Using last equation its possible to build a conditional mean for $p_{i t}^{*}$, which gives:

$p_{i t}^{*}=f(X)$

For the last formula, the function $f(X)$ is just a generic formulation saying that the pair of asset $i$ is a function based on other variables, where $\mathrm{X}$ is a matrix with the information of everything that can explain $P_{i t}^{*}$. The function $\mathrm{f}($.) can be linear or non-linear. In order to simplify, the rest of the discussion is going to be based on a linear formulation using the information of the prices of other assets $^{3}$. Such approach produces:

$p_{i t}^{*}=w_{1} P_{1 t}^{*}+w_{2} P_{2 t}^{*}+w_{3} P_{3 t}^{*}+w_{4} P_{4 t}^{*} \ldots \ldots . w_{m} P_{m t}^{*}$

Simplifying:

$p_{i t}^{*}=\sum_{k=1}^{m} w_{k} P_{k t}^{*}$

\footnotetext{
${ }^{3}$ Any kind of variable can be used in this general formulation, including FF variables, Fama and French (1992).
} 
Inserting the last formula in the first equation gives the final result, Equation [3]:

$$
P_{i t}^{*}=\sum_{k=1}^{m} w_{k} P_{k t}^{*}+\varepsilon_{i t}^{*}
$$

At Equation [3], the value of $w_{k}$ is the linear weight that asset $k$ has in explaining $i$, where $k$ goes from 1 to $m$. For this particular research, three different approaches are going to be used in the weighting scheme (calculation of $w_{k}$ ). More details about the approaches will be given later. For Equation [3], the term $P_{k t}^{*}$ is the normalized price of asset $k$. The choice of $m$ may be arbitrary of not. It's possible to build a dynamic approach, selecting optimal values of $m$ that minimizes a particular objective function, but, for sake of simplicity, the approach at selecting $m$ is arbitrary at this research. After defining the choice of $m$, the next step is to find the $m$ assets that have highest correlation with $i$ in the normalized price state. The normalized price of such assets are referred as $P_{k t}^{*}$, where $k$ goes from 1 to $m$.

The trading rules of this formulation are similar as in the classical version: create a trading sign when the absolute value of $\varepsilon_{i t}^{*}$ is higher than $d$ and take long (short) positions for asset $i$ if the value of $\varepsilon_{i t}^{*}$ is lower (higher) than zero. It's possible to take trading positions on the formed pair of asset $i$, which would require the condition that $\sum_{k=1}^{m} w_{k}=1$ and $w_{k} \geq 0$ in order to form such portfolio, but this is not suggested since it would require the creation of a portfolio with $m$ assets every time that a trading sign is created. Such creation would take a high number of transaction costs, and this can easily eat up the profits from the positions. Given that, the framework tested in this research doesn't allow for trading positions for the artificial pair.

It's important to note that, if some restrictions are made in the formulation given before, it's possible to reach the same formula as in classical trading. This can be done with $m=1$ and with the restriction of $\sum_{k=1}^{m} w_{k}=1$. With that, Equation [3] becomes $P_{i t}^{*}=P_{k t}^{*}+\varepsilon_{i t}^{*}$, and, since $P_{k t}^{*}$ was chosen with the same criteria as in the classical version, it is equal to $p_{i t}^{*}$, Equation [1].

As can be seen from the explanation of the trading process, this proposed version can clearly be labeled as a mean reverting strategy, since the idea is to build a conditional mean for the normalized prices of the series and trade when the error is considered abnormal, hoping for a reversion at the historical behavior. As showed before, the heart of the method is at defining the weights in the formation of the artificial pairs. This can be done in many ways, including parametric or non-parametric models. In order to keep everything simple, this research is going to use three accessible weighting schemes in the multivariate framework. The details about each are given next. 


\subsubsection{Using OLS to Estimate $w_{k}$}

As showed before, one of the main issues about this proposed approach at pairs trading is to build a pair for asset $i$. In a linear framework, it's possible to use least squares to find the coefficients that present the lowest sum of quadratic error between the asset's $i$ normalized price series and the normal price series of the artificial pair. In this framework, the conditional mean of the normalized price of asset $i\left(P_{i t}^{*}\right)$ is addressed as next formula, Equation [4].

$P_{i t}^{*}=w_{1} P_{1 t}^{*}+w_{2} P_{2 t}^{*}+w_{3} P_{3 t}^{*}+w_{4} P_{4 t}^{*} \ldots \ldots . . w_{m} P_{m t}^{*}+\varepsilon_{i t}^{*}$

As said before, the coefficients $w_{k}$ of [4] are going to be estimated with the minimization of the sum of quadratic error, $\sum_{t=1}^{T}\left[\left(\varepsilon_{i t}^{*}\right)^{2}\right]$. More details about the least squares method can be found in any undergraduate econometrics textbook, including Maddala (2001). One should notes that, since $P_{k t}^{*}$ are chosen such that the correlation with $P_{i t}^{*}$ is maximum then there is a substantial multicolinearity problem with the model at [4]. Such problem could be solved by reduction methods but, in order to keep everything simple, no correction for multicolinearity is performed here. Notes that the artificial pair cannot be traded unless some constraints are made to the values of the coefficients, which is not the case for this tested method since the artificial pair will not be traded due to the transaction costs involved.

\subsubsection{Using Equal Weights to Estimate $w_{k}$}

In this approach the weighting scheme is the simplest one. Since the choice of $k$ (number of assets to model $P_{i t}^{*}$ ) is arbitrary, the artificial pair of asset $i$ is just the average of the $k$ chosen assets. Such framework produces Equation [5].

$$
P_{i t}^{*}=\frac{1}{m} \sum_{k=1}^{m} P_{k t}^{*}+\varepsilon_{i t}^{*}
$$

For Equation [5], it's possible to see that $w_{k}=\frac{1}{m}$, where $m$ is the arbitrary number of assets chosen to build $p_{i t}^{*}$. 


\subsubsection{Using a Correlation Weighting Scheme}

This framework is the most flexible one since it uses the information on the correlation vector. Defining $\rho_{k}$ as the correlation of the normalized price series $k$ with the normalized price of $i$, this approach will calculate the weights using $w_{k}=\frac{\rho_{k}}{\sum_{k=1}^{m} \rho_{k}}$. With this formulation, Equation [3] becomes [6].

$$
P_{i t}^{*}=\sum_{k=1}^{m}\left[\frac{\rho_{k}}{\sum_{k=1}^{m} \rho_{k}} P_{k t}^{*}\right]+\varepsilon_{i t}^{*}
$$

As can be seem from [6], this approach is very flexible, using weights according to the value of correlations between the normalized price series. If the $m$ chosen assets present very similar values of $\rho_{k}$, then this approach will be very close to the last one, which uses equal weights.

The main advantage of this framework is that it will be flexible on the weights, giving more values to those normalized prices that have higher values of correlation and less weight to those with low values. This in especially good for the cases where the modeled asset $i$ is not so popular and only a few other stocks present similar behavior. For this particular case, the weighting scheme is going to give more importance to the assets with high correlation, as opposed to the equal weighting scheme.

\subsection{Assessing Performance of the Strategy}

One of the concerns of this study is to evaluate the performance and risk of the multivariate version of pairs trading strategy against a naïve approach. For that purpose, the strategy's returns are going to be compared against a properly weighted portfolio and also against random trading signals (bootstrap method). The details about the return's calculations are given in the next topics.

\subsubsection{Calculation of Strategy's Returns}

The calculation of the strategy's total return is going to be executed according to the next formula, Equation [7].

$$
R_{E}=\sum_{t=1}^{T} \sum_{i=1}^{n} R_{i t} I_{i t}^{L \& S} W_{i t}+\left(\sum_{t=1}^{T} \sum_{i=1}^{n} T c_{i t}\right)\left[\ln \left(\frac{1-C}{1+C}\right)\right]
$$


Where:

$R_{i t} \quad$ Real return of asset $i$ on time $t$, calculated by $\ln \left(\frac{P_{i t}}{P_{i t-1}}\right)$;

$I_{i t}^{L \& S} \quad$ Dummy variable that takes value 1 if a long position is created for asset $i$, value -1 if a short position is created and 0 otherwise. When a long position is made at time $t$, this variable is going to be addressed as $I_{i t}^{L}$ and as $I_{i t}^{S}$ for short positions;

$W_{i t} \quad$ Weighting variable that controls for portfolio construction at time $t$. In this particular paper the simulated portfolio is equal weight, meaning that each trading position will have the same weight at time $t$, that is $W_{i t}=\frac{1}{\sum_{i=1}^{n}\left|I_{i t}^{L \& S}\right|}$. Naturally, the sum of $W_{i t}$ for all assets is equal to 1 or zero (no trading position at time $t$ );

$T c_{i t} \quad$ Dummy variable that takes value 1 if a transaction is made for asset $i$ on time $t$ and zero otherwise $^{4}$

C Transaction cost per operation (in percentage);

$T \quad$ Number of observations on the whole trading period;

For Equation [7], the basic idea is to calculate the returns from the strategy accounting for transaction costs. The first part of [7], $\sum_{t=1}^{T} \sum_{i=1}^{n} R_{i t} I_{i t}^{L \& S} W_{i t}$, calculates the total raw return of the strategy. Every time a long and short position is created for asset $i$, the raw return of the simulated portfolio on time $t$, is $\sum_{i=1}^{n} R_{i t} I_{i t}^{L \& S} W_{i t}$, that is, the prospected returns multiplied by their corresponding weight in the portfolio. Since $t$ goes from 1 to $T$, is necessary to sum such returns, which gives the final result for the first part of [1], $\sum_{t=1}^{T} \sum_{i=1}^{n} R_{i t} I_{i t}^{L \& S} W_{i t}$.

The second part of Equation [7] has the objective of accounting for transaction costs. As an example, suppose that the trading cost of buy and selling one stock is $C$, which is expressed as a percentage of the transaction price. If a stock is purchased at price $P_{B}$ and sold at price $P_{S}$, then the real buy and sell prices, including transaction costs, are $P_{B}(1+C)$ and $P_{S}(1-C)$. Taking the

\footnotetext{
${ }^{4}$ It's important to distinguish the values of $I_{i t}^{L \& S}$ (long and short positions) from $T c_{i t}$ (transaction dummy). The values of $T c_{i t}$ are derived from the vector $I_{i t}^{L \& S}$, but they are not equal. For example, suppose a long position is created for asset $i$ on time t- 1 and also on time $t$, only. The vector of $I_{i t}^{L}$ is going to have values of 1 to time $t-l$ and $t$, but the vector of $T c_{i t}$ has only value 1 for time $t-1$, since for $t$, the asset was already in the portfolio, so there is no need to buy it again. The same is true for short positions.
} 
logarithm return of the operation results on the formula $R=\ln \left(\frac{P_{S}(1-C)}{P_{B}(1+C)}\right)$. Using logarithm properties, the previous equation becomes $R=\ln \left(\frac{P_{S}}{P_{B}}\right)+\ln \left(\frac{1-C}{1+C}\right)$. It's possible to see from this result that the return for this operation has two separate components, the logarithm return from difference between selling and buying price and also the term $\ln \left(\frac{1-C}{1+C}\right)$, which accounts for the transaction cost on the whole operation. This exemplified result basically states that the transaction cost for one operation (buy\&sell) is $\ln \left(\frac{1-C}{1+C}\right)$.

Returning to the analysis of the second part of Equation [1], since $\ln \left(\frac{1-C}{1+C}\right)$ is the transaction cost of one operation, logically the term $\left(\sum_{t=1}^{T} \sum_{i=1}^{n} T c_{i t}\right)$ is just the number of operations made by the trading strategy. Is important to notes that, since $\frac{1-C}{1+C}$ is always less than one because $\mathrm{C}$ is always positive and higher than zero, then the value of $\ln \left(\frac{1-C}{1+C}\right)$ is always negative, meaning that the transaction costs are going to be subtracted from the strategy' returns, which is an intuitive result.

\subsubsection{Evaluation of Strategy' Returns}

In order to evaluate the performance of the strategy, it's necessary to compare it to a naïve approach. If the strategy performs significantly better than an out-of-skill investor, then such trading rule has value. This is the main idea that will conduct both methods used in this research to evaluate the performance of the proposed approach. The approaches described here are computation of excessive return over a naïve buy\&hold rule and the more sophisticated bootstrap method of random trading signals.

\subsubsection{Computation of Excessive Return of a Naïve Portfolio}

The calculation of excessive return is the simplest approach to evaluate a trading strategy. The idea is quite simple: verify how does the tested strategy exceeds a naïve trading rule in terms of profitability. In this case, the naïve rule is the buy\&hold of a properly weighted portfolio for comparison with the long positions and a "sell\&unhold" for the short positions.

The return of the naïve approach, over the whole number of assets, is based on the following formula, Equation [8]. 


$$
R_{N E}=\sum_{i=1}^{n} P_{i}^{L} \sum_{t=1}^{T} R_{i t}+\sum_{i=1}^{n} P_{i}^{S} \sum_{t=1}^{T} R_{i t}+2 n \ln \left(\frac{1-C}{1+C}\right)
$$

For Equation [8], the value of $P_{i}^{L}$ and $P_{i}^{S}$ is just the proportion of days, related to the whole trading period, that the strategy created long and short positions for asset $i$. Formally, $P_{i}^{L}=\frac{\sum_{i=1}^{T} I_{i t}^{L}}{T}$ and $P_{i}^{S}=\frac{\sum_{t=1}^{T} I_{i t}^{S}}{T}$. Notes that, in the calculation of $P_{i}^{S}$, the sum of the short positions is always negative or equal to zero, since $I_{i t}^{S}$ takes values -1 and 0 , only.

Since pairs trading strategy uses two different types of positions in the stock market, long for the hope of a price increase and short for the hope of a price decrease, it's necessary to construct a naïve portfolios that also takes use of such positions. This is the function of the terms $\sum_{i=1}^{n} P_{i}^{L} \sum_{t=1}^{T} R_{i t}$ and $\sum_{i=1}^{n} P_{i}^{S} \sum_{t=1}^{T} R_{i t}$, where the first simulates a buy\&hold (long positions) of a properly weighted portfolio and the second simulates a "sell\&unhold" (short positions) scheme for another properly weighted portfolio. The weights in both terms are derived from the number of long and short positions taken on each asset, as was showed before. The higher the number of long and short signals a strategy makes for asset $i$, higher the weight that such stock will have on the simulated portfolio. It's clear to see from Equation [8] that, if $P_{i}^{S}=P_{i}^{L}$, which is a perfectly hedged position for asset $i$ in the benchmark portfolio, the terms $\sum_{i=1}^{n} P_{i}^{L} \sum_{i=1}^{T} R_{i t} \sum_{i=1}^{n} P_{i}^{S} \sum_{i=1}^{T} R_{i t}$ nulls each other and the contribution of accumulated return for this respective asset in the benchmark portfolio is just the transaction cost for setting up the portfolios.

It should be notes that the calculation of return at Equation [8] doesn't include $W_{i t}$ variable as in Equation [7]. This happens because the refereed equation is calculating the sum of expected returns of a naïve long and short positions for all assets, and not the return of the simulated portfolio over time (Equation [7]).

As can be seen from Equation [8], one of the premises of the research is that the transaction cost per operation is the same for long and short positions. The last term of [8] is the transaction costs for opening positions (making the portfolio) and trade them at the end of the period. In this case, the number of trades required to form and close the two portfolios is $2 n$, where $n$ is the number of researched assets.

The excessive return for the strategy is given by the difference between [7] and [8], which forms the final formula for computing excessive return, Equation [9].

$$
R_{E}^{*}=\sum_{t=1}^{T} \sum_{i=1}^{n} R_{i t} I_{i t}^{L \& S} W_{i t}-\sum_{i=1}^{n} P_{i}^{L} \sum_{t=1}^{T} R_{i t}-\sum_{i=1}^{n} P_{i}^{S} \sum_{t=1}^{T} R_{i t}+\left(\sum_{i=1}^{n} \sum_{t=1}^{T} T c_{i t}-2 n\right)\left[\ln \left(\frac{1-C}{1+C}\right)\right]
$$


Analyzing Equation [9], the maximization of $R_{E}^{*}$, which is the objective of any trading strategy, is given by the maximization of $\sum_{t=1}^{T} \sum_{i=1}^{n} R_{i t} I_{i t}^{L \& S} W_{i t}$, minimization of $\sum_{i=1}^{n} P_{i}^{L} \sum_{t=1}^{T} R_{i t}$ and $\sum_{i=1}^{n} P_{i}^{S} \sum_{t=1}^{T} R_{i t}$ and also minimization of $\left(\sum_{i=1}^{n} \sum_{t=1}^{T} T c_{i t}-2 n\right)$, since $\left[\ln \left(\frac{1-C}{1+C}\right)\right]$ is a constant. The conclusion about this analysis is intuitive because the strategy is only going to be successful if it efficiently creates long and short positions on the stocks, keeping the transaction costs and the benchmark returns at low values. Short story, make more money with less trades.

\subsubsection{Bootstrap Method for Assessing Pairs Trading Performance}

The bootstrap method represents a way to compare the trading signals of the strategy against pure chance. The basic idea is to simulate random entries in the market, save the values of a performance indicator for each simulation and count the percentage number of times that those random entries were worst than the performance obtained in the tested strategy. It should be notes that each trading strategy takes different number of long and short positions and for a different number of days. Such information is also taken in account at the random simulations. Before applying the algorithm, separately, for long and short position, it should be calculated the median number of days (nDays_Long and nDays_Short) that the strategy has been trading in the market and also the median number of assets (nAssets_Long and nDays_Short).

The steps are:

1. With the values of the nDays and nAssets for long and short, define $n$ Days random entries in the market for nAssets number of assets. Again, making it clear, this procedure should be repeated for each type of trading position (long and short). The output from this step is a trading matrix which has, only, values 1 (long position), -1 (short position) or zero (no transaction).

2. Taking as input the trading matrix and the transaction costs, the portfolio is build with equal weights, resulting in a vector with the returns of the trading signals over time, $R_{t}=\sum_{i=1}^{n} R_{i t} W_{i t}^{R N D}$, where $R_{i t}$ is the return for asset $i$ at time $t, W_{i t}^{R N D}$ is corresponding portfolio weight of asset $i$ at time $t$, which is build with the random trading signals from last step. Such vector is then used for calculation of the performance indicators (eg. annualized raw return, annualized standard deviation, annualized sharpe ratio).

3. Repeat steps 1 and $2 N$ number of times, saving the performance indicator value for each simulation.

After a considerable number of simulations, for example $N=5000$, the result for the bootstrap method is going to be a distribution of performance indicators. The test here is to verify the percentage of cases that the tested strategy has beaten comparing with the use of random trading. The performance indicators used in this particular research are annualized raw return, annualized standard deviation and the annualized sharpe ratio. 
As an example, the next ilustraton is the histogram of the accumulated returns from the use of bootstrap algorithm ${ }^{5}$ for the daily database with options: $N=5.000, n$ Days_Long=400, $n$ Days_Long $=250, n$ Assets_Long $=5$, nAssets_Short $=3$ and with zero transaction cost $(C=0)$.

Figure 2 - Histogram of the annualized raw returns from the Random Trading signals

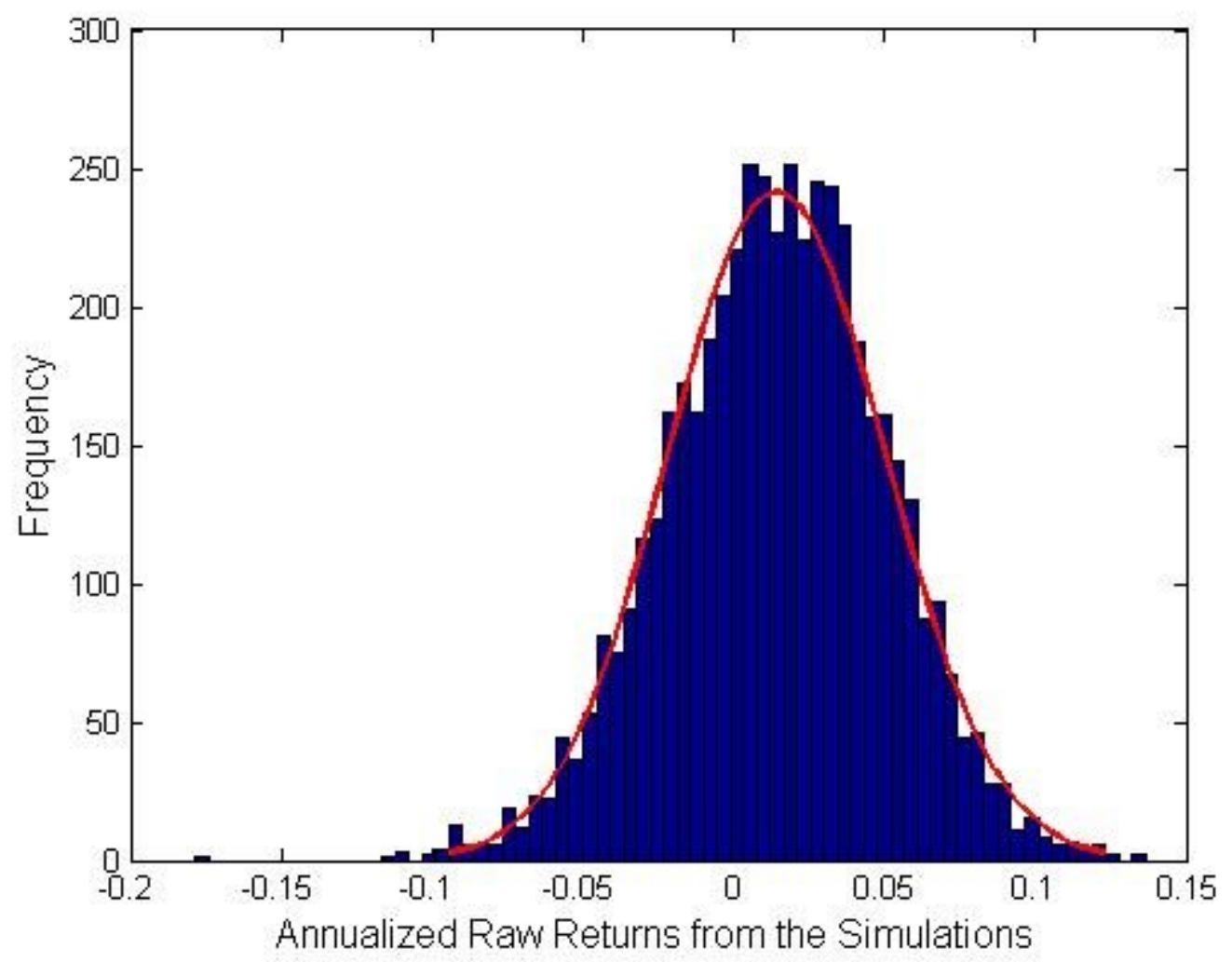

Figure 2 shows that, considering the options given to the algorithm, an out-of-skill investor would earn, in average, an annualized raw return of approximately $1.5 \%$. The best case for the random trading signals is approximately $15 \%$ and the worst is $-10 \%$. One can also see that the distribution can be well pictured by a normal likelihood (the line).

The next step in using this bootstrap approach is to count the number of times that the performance indicator from the tested strategy is better ${ }^{6}$ than the simulated performance indicators from the random trading signal and divide that by the number of simulations. The result is a percentage showing how many random signals the tested strategy has beaten. If such strategy has value, it would produce percentages close to $80 \%$. If it is just a case of chance, it would give a percentage close to $50 \%$ and, if the strategy doesn't present any value, it would result in a percentage close to $20 \%$, meaning that, in this case, it's possible to get higher returns

\footnotetext{
${ }^{5}$ The algorithm used is kindly called monkey trading and can be found at author's matlab's exchange site, together with the classical pairs trading algorithm.

${ }^{6}$ Better could mean higher or lower, depending of which performance indicator is being calculated. For instance, a higher annualized return is better, while a lower annualized standard deviation is preferred
} 
by just using a random seed to select assets and days to trade. One way of analyzing the result of the bootstrap algorithm is that it compares the selections made by the trading strategy, that is, the days and assets to trade, against an expected value of the indicator for the same days and number of trades over the full researched data.

\section{Database for the Research}

The database for this research is based on the $57^{7}$ most liquids stocks from the Brazilian financial market between the periods of 2000 and 2006. The training period of the tested strategies is based on a moving window with approximately 2 year of trading data (494 days). The artificial pair for each stock is updated at each 10 days.

As an example, for trading at time $t=495$ is going to be used all information from 1 to 494 in order to find and build each stock's pairs. For time $t=496$ the distances are recalculated, but the weights of the pairs are the same ones used at $t=495$. At time $t=505$ the pairs of each asset are updated and the weights at Equation [3] are recalculated and by using the window from observation 11 to 504. This process is repeated for the whole data. The normalization of the price series is also made using this moving windows structure, that is, at each arrival of a new observation, for each stock, a new mean and standard deviation of the prices is obtained and used for calculating the normalized prices.

It should be pointed out that no future information is used to construct the trading signs. For each trading decision at time $t$, the information used is based, only, on $t$-window +1 to $t-1$. The only future information used for this research is in the data used since it was searched the most liquid stocks from 2000 to 2006. This was a necessary procedure to avoid illiquid stocks. A possible approach for avoiding this would be to have a time varying research database, where the stocks are selected according to its liquidity from $t$-window +1 to $t-1$. But, this is not the method used in this paper.

\section{Results}

The three weighting schemes of the proposed multivariate pairs trading were executed ${ }^{8}$ for the equity database, forming a dynamic portfolio which changes its composition over time (long and short positions). Next, Table 1, the results from the profitability point of view are presented. The values were calculated with fixed $\mathrm{C}=0.1 \%{ }^{9}, m=5$ and for each value of the threshold $d(d=0.5 \ldots$ 2).

\footnotetext{
${ }^{7}$ The choice for 57 assets was that those were the most liquid among the firstly screened 100 that presented $98 \%$ of valid closing prices.

${ }^{8}$ All the calculations needed for this research were performed using MatLab.

${ }^{9}$ The trading cost of $0.1 \%$ per operation is a realistic value for the Brazilian market. It can be easily achieved with a relatively small amount of $20.000 \mathrm{R}$, which, today (November 2006), is something close to 9.000 USD.
} 
Table 1 - Profitability Analysis for the Three Versions of Multivariate Pairs Trading Strategy

\begin{tabular}{|c|c|c|c|c|c|c|c|c|c|}
\hline \multicolumn{10}{|c|}{ Panel A - Multivariate Pairs Trading with OLS (Ordinary Least Squares) } \\
\hline \multirow{2}{*}{$\begin{array}{l}\text { Value of } \\
\quad d\end{array}$} & \multicolumn{3}{|c|}{$\begin{array}{c}\text { Total Raw Return (with transaction } \\
\text { costs) }\end{array}$} & \multicolumn{3}{|c|}{$\begin{array}{c}\text { Total Excessive Returns (over } \\
\text { Benchmark) }\end{array}$} & \multirow{2}{*}{$\begin{array}{c}\% \text { of days } \\
\text { in the } \\
\text { Market }\end{array}$} & \multirow{2}{*}{$\begin{array}{l}\text { Annualized } \\
\text { Raw Return* }\end{array}$} & \multirow{2}{*}{$\begin{array}{c}\% \text { of } \\
\text { Random } \\
\text { Portfolios } \\
\text { Beaten } \\
\text { Annualized } \\
\text { Raw } \\
\text { Returnn } \\
\end{array}$} \\
\hline & $\begin{array}{l}\text { Long } \\
\text { Positions }\end{array}$ & $\begin{array}{l}\text { Short } \\
\text { Positions }\end{array}$ & Total & $\begin{array}{l}\text { Long } \\
\text { Positions }\end{array}$ & $\begin{array}{c}\text { Short } \\
\text { Positions }\end{array}$ & Total & & & \\
\hline 0.50 & $53.10 \%$ & $-135.48 \%$ & $-130.74 \%$ & $-118.46 \%$ & $164.09 \%$ & -2.1470 & 10.0 & . & $0.00 \%$ \\
\hline 0.60 & $88.63 \%$ & $-137.57 \%$ & $-103.59 \%$ & $-15.56 \%$ & $76.99 \%$ & $6.78 \%$ & $\%$ & & $0.00 \%$ \\
\hline 0.70 & $27.67 \%$ & $-122.24 \%$ & $-122.23 \%$ & $-36.48 \%$ & $8.87 \%$ & $-35.27 \%$ & & & $0.00 \%$ \\
\hline 0.80 & $-21.39 \%$ & -10 & $-110.61 \%$ & $-64.30 \%$ & & & & & $0.00 \%$ \\
\hline 0.90 & $-59.20 \%$ & $-68.13 \%$ & $-115.98 \%$ & $-89.56 \%$ & & $-60.71 \%$ & & & $0.00 \%$ \\
\hline 1.00 & & & $-69.42 \%$ & -37 & & & & & $0.00 \%$ \\
\hline 1.10 & & & -45 & -12 & & $\%$ & & & $0.00 \%$ \\
\hline 1.2 & & & & & & & & & $100.00 \%$ \\
\hline 1.3 & $\%$ & & & & & & & & $99.60 \%$ \\
\hline 1.4 & $\%$ & & & & & & & & $100.00 \%$ \\
\hline 1.5 & & & & & & & & & 100 \\
\hline 1.6 & & & & & & & & & 100 \\
\hline 1.7 & & & & & & & & & $\%$ \\
\hline 1.8 & & & & & & & & & $\%$ \\
\hline 1. & $\%$ & & & & & & & & $0 \%$ \\
\hline 200 & & $08 \%$ & $39.67 \%$ & $0.09 \%$ & $53.54 \%$ & $50.33 \%$ & $4.31 \%$ & & $100.00 \%$ \\
\hline \multicolumn{10}{|c|}{ Panel B -Multivariate Pairs Trading with Equal Weigths } \\
\hline \multirow{2}{*}{$\begin{array}{l}\text { Value of } \\
\quad d\end{array}$} & \multicolumn{3}{|c|}{$\begin{array}{l}\text { Total Raw Return (with transaction } \\
\text { costs) }\end{array}$} & \multicolumn{3}{|c|}{$\begin{array}{c}\text { Total Excessive Returns (over } \\
\text { Benchmark) }\end{array}$} & \multirow{2}{*}{$\begin{array}{l}\% \text { of days } \\
\text { in the } \\
\text { Market }\end{array}$} & \multirow{2}{*}{$\begin{array}{l}\text { Annualized } \\
\text { Raw Return* }\end{array}$} & \multirow{2}{*}{$\begin{array}{c}\% \text { of } \\
\text { Random } \\
\text { Portfolios } \\
\text { Beaten** } \\
\text { Annualized } \\
\text { Raw } \\
\text { Return } \\
\end{array}$} \\
\hline & $\begin{array}{l}\text { Long } \\
\text { Positions }\end{array}$ & $\mathrm{SH}$ & Total & $\begin{array}{l}\text { Long } \\
\text { Positions }\end{array}$ & $\begin{array}{l}\text { Short } \\
\text { Positions }\end{array}$ & al & & & \\
\hline 0.50 & $7 \%$ & $\%$ & $-112.56 \%$ & -68 & $\%$ & & & & $0.00 \%$ \\
\hline 0.60 & $31 \%$ & $-112.59 \%$ & $-95.39 \%$ & $-478.27 \%$ & 559.1 & $74.82 \%$ & & & $0.00 \%$ \\
\hline 0.70 & & & -6 & -30 & & & & & \\
\hline 0.8 & & & & & & & & & \\
\hline 0.90 & & & -39 & -12 & 23 & $\%$ & 5 & & $0.10 \%$ \\
\hline 1.00 & $82 \%$ & -5 & $37.34 \%$ & -29 & 172 & $119.90 \%$ & & & $100.00 \%$ \\
\hline 1.10 & $65.13 \%$ & $-50.25 \%$ & $21.61 \%$ & $-40.54 \%$ & $121.76 \%$ & $87.95 \%$ & $41.42 \%$ & & $100.00 \%$ \\
\hline 1.20 & $36 \%$ & $-58.54 \%$ & $61.04 \%$ & & & $111.90 \%$ & 35.0 & & $100.00 \%$ \\
\hline 1.3 & & & 96.6 & & & $137.72 \%$ & & & $100.00 \%$ \\
\hline 1.40 & $31.37 \%$ & $-8.32 \%$ & $56.33 \%$ & -13. & $65.30 \%$ & $85.16 \%$ & $22.67 \%$ & & $100.00 \%$ \\
\hline 1.50 & $63.17 \%$ & $-30.13 \%$ & $33.37 \%$ & $26.89 \%$ & $24.90 \%$ & $52.11 \%$ & $18.96 \%$ & $8.37 \%$ & $100.00 \%$ \\
\hline 1.60 & $30.78 \%$ & $-36.96 \%$ & $10.17 \%$ & $4.02 \%$ & $7.80 \%$ & $28.18 \%$ & $15.85 \%$ & $2.55 \%$ & $98.90 \%$ \\
\hline 1.70 & $38.16 \%$ & $-28.29 \%$ & $22.57 \%$ & 19.1 & 7.6 & $39.53 \%$ & 11.7 & 5.66 & $99.90 \%$ \\
\hline 1.8 & & & & $30.72 \%$ & & & 10. & $10.67 \%$ & $100.00 \%$ \\
\hline 1.90 & $75.83 \%$ & $1.68 \%$ & $57.34 \%$ & $64.99 \%$ & $23.32 \%$ & $68.13 \%$ & $8.02 \%$ & $14.38 \%$ & $100.00 \%$ \\
\hline 2.00 & $63.42 \%$ & $0.03 \%$ & $49.81 \%$ & $55.43 \%$ & $16.29 \%$ & $58.08 \%$ & $5.62 \%$ & $12.49 \%$ & $100.00 \%$ \\
\hline
\end{tabular}




\begin{tabular}{|c|c|c|c|c|c|c|c|c|c|}
\hline \multicolumn{10}{|c|}{ Panel C - Multivariate Pairs Trading using a Correlation Weighting Scheme } \\
\hline \multirow{2}{*}{$\begin{array}{l}\text { Value of } \\
\quad d\end{array}$} & \multicolumn{3}{|c|}{$\begin{array}{l}\text { Total Raw Return (with transaction } \\
\text { costs) }\end{array}$} & \multicolumn{3}{|c|}{$\begin{array}{c}\text { Total Excessive Returns (over } \\
\text { Benchmark) }\end{array}$} & \multirow{2}{*}{$\begin{array}{c}\% \text { of days } \\
\text { in the } \\
\text { Market }\end{array}$} & \multirow{2}{*}{$\begin{array}{l}\text { Annualized } \\
\text { Raw Return* }\end{array}$} & \multirow{2}{*}{$\begin{array}{c}\% \text { of } \\
\text { Random } \\
\text { Portfolios } \\
\text { Beaten }^{* *} \\
\text { Annualized } \\
\text { Raw } \\
\text { Return } \\
\end{array}$} \\
\hline & $\begin{array}{l}\text { Long } \\
\text { Positions }\end{array}$ & $\begin{array}{l}\text { Short } \\
\text { Positiol }\end{array}$ & Total & $\begin{array}{l}\text { Long } \\
\text { Positions }\end{array}$ & $\begin{array}{c}\text { Short } \\
\text { Positions }\end{array}$ & Total & & & \\
\hline 0.5 & $\%$ & $-138.74 \%$ & $\%$ & -624. & 788.7 & 19 & & & $0.00 \%$ \\
\hline 0.60 & & & -103.4 & -429.5 & & & & & $0.00 \%$ \\
\hline 0.70 & $5 \%$ & & $-7 €$ & $-259 . \varepsilon$ & & $\%$ & & & $0.00 \%$ \\
\hline 0.80 & $9 \%$ & -11 & $33 \%$ & $-165.46 \%$ & 32 & 16 & & & $0.00 \%$ \\
\hline 0.90 & $23.88 \%$ & -92 & $-59.04 \%$ & $-116.39 \%$ & 247 & $140.60 \%$ & & & $0.00 \%$ \\
\hline 1.00 & $43.87 \%$ & -81.0 & $-14.01 \%$ & $-50.03 \%$ & 177.4 & $150.64 \%$ & & & $16.50 \%$ \\
\hline 1.10 & $04 \%$ & & $-5.44 \%$ & -13.8 & & & & & $54.70 \%$ \\
\hline 1.20 & & & & 30.3 & & & & & $100.00 \%$ \\
\hline 1.30 & $11 \%$ & -25 & 50.7 & 71.5 & $\%$ & $14 \varepsilon$ & $\%$ & & $100.00 \%$ \\
\hline 1.40 & $60.12 \%$ & $-25.30 \%$ & $57.52 \%$ & $48.25 \%$ & $.41 \%$ & $142.36 \%$ & & $\%$ & $100.00 \%$ \\
\hline 1.50 & $37.88 \%$ & $-19.81 \%$ & $23.50 \%$ & $33.28 \%$ & 57.41 & $96.12 \%$ & & & $99.80 \%$ \\
\hline 1.60 & $41 \%$ & $-35.28 \%$ & 19 & 49.0 & 28 & $85.77 \%$ & & 4.9 & $99.50 \%$ \\
\hline 1.70 & $82.56 \%$ & $-14.78 \%$ & $65.62 \%$ & $88.04 \%$ & 39.0 & $124.98 \%$ & & & $100.00 \%$ \\
\hline 1.80 & $93.39 \%$ & $24.63 \%$ & $86.67 \%$ & $101.55 \%$ & $68.85 \%$ & $139.06 \%$ & $12.24 \%$ & 21.7 & $100.00 \%$ \\
\hline 1.90 & $84.87 \%$ & $-2.38 \%$ & $59.95 \%$ & $94.44 \%$ & $33.57 \%$ & $105.47 \%$ & $9.03 \%$ & $15.03 \%$ & $100.00 \%$ \\
\hline 2.00 & $87.02 \%$ & $9.95 \%$ & $72.33 \%$ & $98.20 \%$ & $38.25 \%$ & $111.81 \%$ & $8.12 \%$ & $18.14 \%$ & $100.00 \%$ \\
\hline
\end{tabular}

* The annualized raw return is calculated by taking the total raw return, divide it by the total number of days in the trading sample (in this case 997) and then multiplying the result by 250 (average number of business days in one year).

** The bootstrap method was conducted with 1000 simulations for each value of $d$. Simple experiments showed that this is a reasonable number of simulations (an increase in $N$ didn't changed significantly the results).

*** The percentage showed at this column is the number of beated portfolios given the specific performance statistic (in this case annualized raw return).

**** This column is calculated by counting the number of days where there was at least one trading position (long or short) and dividing the result by the total number of trading days at the sample (in this case 997).

The values presented at Table 1 were constructed using the equation described at earlier topics of this paper. For instance, the raw returns column is calculated according to Equation [2]. The excessive returns columns are calculated with Equation [4]. The last column is calculated using the bootstrap procedure described at the past section of the paper.

The first values to be analyzed at Table 1 are the raw returns obtained from the different approaches (panels) of multivariate pairs trading. For $d=1.2$ to $d=2$, most of the values at Panels $\mathrm{A}, \mathrm{B}$ and $\mathrm{C}$ are positive, meaning that the returns of the strategy after transaction costs are mostly positive. For the excessive returns column, the values are all positive for Panels B and C but not for Panel A. One should also notes that the excessive returns for short positions were in great majority positive and high in value. Partly, this is happening because the benchmark portfolio is underperforming significantly since the data used for the research is particularly bullish ${ }^{10}$. Given that the benchmark underperforms brutally, the positions from the short signals yields a high excessive return. One should be careful when concluding performance based only on the static benchmark method given here.

\footnotetext{
${ }^{10}$ From the period of 2001 to 2006, Ibovespa, which is the broad market index for Brazilian Market, grew from 17.672 to 38.382 points.
} 
Another important information in Table 1 is the number of days that the strategy was trading in the market for each approach. For all panels, it's possible to see that the percentage of days in the market decreases as $d$ grows. This is expected since $d$ controls for abnormal behavior and, when the threshold for such case increases, less and less cases are found. Comparing the percentage of days in the market for the different approaches (panels), it's clear that the OLS method, Panel 1, had much less trades then the other ones. This is explained by the fact that the weighting scheme used in Panel A is concerned in statistically replicating the modeled series within a calibration framework, meaning that finding abnormal behavior, which is the core of pairs trading, should occur less than a non calibration type of framework, Panels B and C.

Comparing the results for the different panels, one can see that the panel B (equal weight scheme) and $\mathrm{C}$ (correlation weight scheme) yielded higher raw and excessive return than Panel A (OLS weight scheme). But, at the same time, the OLS method produced less trading signals (stayed less days in the market), therefore produced less risk. A greater view of the risk of the strategies is given in the next section of the paper.

When comparing the results at Table 1 for Panel B against Panel C, the values for percentage of days in the market and total raw returns are, for the different values of $d$, quite similar. But, when looking at the total excessive return at Panel $\mathrm{C}$, the results for long and short positions (and both combined) are higher than Panel B, therefore showing that, when it comes to excess profitability, a higher performance is found for the correlation weighting scheme.

The main conclusion after the profitability analysis from the trading strategies is that the proposed version of pairs trading performs significantly better than chance and provides positive raw and excessive returns after transactions costs. Such evidence is consistently found over the different versions tested in this research and over different values of the threshold parameter $(d)$. The best case, as stated before, is for the correlation weighting scheme (Panel C).

The risks provided from the trading signals at the different methods are assessed next. The analysis will cover the systematic risk (beta), jensen's alphas, annualized standard deviation of the returns and annualized sharpe ratio. The analysis will also cover the bootstrap method for the performance indicators.

Table 2 - Risk Analysis for Multivariate Pairs Trading

\begin{tabular}{|c|c|c|c|c|c|c|c|c|}
\hline \multicolumn{9}{|c|}{ Panel A - Multivariate Pairs Trading with OLS (Ordinary Least Squares) } \\
\hline \multirow[b]{2}{*}{ Value of $d$} & \multicolumn{2}{|c|}{ Beta $^{\star \star \star *}$} & \multicolumn{2}{|c|}{$\begin{array}{l}\text { Jensen's } \\
\text { Alpha }^{* \star \star \star}\end{array}$} & \multirow{2}{*}{$\begin{array}{l}\text { Annualized } \\
\text { Standard } \\
\text { Deviation* }\end{array}$} & \multirow{2}{*}{$\begin{array}{l}\text { Annualized } \\
\text { Sharpe }^{\star *}\end{array}$} & \multicolumn{2}{|c|}{$\begin{array}{c}\% \text { of Random Portfolios } \\
\text { Beaten*** }\end{array}$} \\
\hline & Value & Prob & Value & Prob & & & $\begin{array}{l}\text { Annualized } \\
\text { Standard } \\
\text { Deviation }\end{array}$ & $\begin{array}{l}\text { Annualized } \\
\text { Sharpe }\end{array}$ \\
\hline 0.5 & -0.066 & 0.011 & -0.001 & 0.006 & 0.227 & -1.446 & $0.00 \%$ & $7.40 \%$ \\
\hline 0.6 & -0.076 & 0.012 & -0.001 & 0.070 & 0.267 & -0.973 & $0.00 \%$ & $18.80 \%$ \\
\hline 0.7 & -0.072 & 0.040 & -0.001 & 0.058 & 0.306 & -1.003 & $0.00 \%$ & $11.70 \%$ \\
\hline 0.8 & -0.051 & 0.160 & -0.001 & 0.093 & 0.315 & -0.880 & $0.00 \%$ & $15.10 \%$ \\
\hline 0.9 & -0.066 & 0.075 & -0.001 & 0.089 & 0.323 & -0.899 & $0.00 \%$ & $12.40 \%$ \\
\hline 1.0 & -0.047 & 0.216 & -0.001 & 0.326 & 0.332 & -0.524 & $0.00 \%$ & $30.60 \%$ \\
\hline 1.1 & -0.060 & 0.121 & 0.000 & 0.561 & 0.341 & -0.332 & $0.00 \%$ & $45.40 \%$ \\
\hline 1.2 & -0.058 & 0.144 & 0.000 & 0.638 & 0.346 & 0.198 & $0.00 \%$ & $74.40 \%$ \\
\hline 1.3 & -0.063 & 0.121 & 0.000 & 0.829 & 0.353 & 0.068 & $0.00 \%$ & $66.00 \%$ \\
\hline 1.4 & -0.065 & 0.104 & 0.000 & 0.772 & 0.349 & 0.103 & $0.00 \%$ & $70.60 \%$ \\
\hline
\end{tabular}




\begin{tabular}{|c|c|c|c|c|c|c|c|c|}
\hline 1.5 & -0.067 & 0.089 & 0.000 & 0.518 & 0.344 & 0.280 & $0.00 \%$ & $77.20 \%$ \\
\hline 1.6 & -0.069 & 0.079 & 0.000 & 0.482 & 0.343 & 0.307 & $0.00 \%$ & $74.60 \%$ \\
\hline 1.7 & -0.077 & 0.046 & 0.001 & 0.453 & 0.338 & 0.325 & $0.00 \%$ & $78.40 \%$ \\
\hline 1.8 & -0.034 & 0.333 & 0.000 & 0.506 & 0.309 & 0.309 & $0.00 \%$ & $76.80 \%$ \\
\hline 1.9 & -0.034 & 0.290 & 0.000 & 0.437 & 0.285 & 0.362 & $0.00 \%$ & $77.40 \%$ \\
\hline 2.0 & -0.025 & 0.439 & 0.000 & 0.458 & 0.282 & 0.353 & $0.00 \%$ & $96.70 \%$ \\
\hline \multicolumn{9}{|c|}{ Panel B -Multivariate Pairs Trading with Equal Weigths } \\
\hline \multirow[b]{2}{*}{ Value of $d$} & \multicolumn{2}{|c|}{ Beta $^{\star \star \star *}$} & \multicolumn{2}{|c|}{$\begin{array}{l}\text { Jensen's } \\
\text { Alpha**** }\end{array}$} & \multirow{2}{*}{$\begin{array}{c}\text { Annualized } \\
\text { Standard } \\
\text { Deviation* }\end{array}$} & \multirow{2}{*}{$\begin{array}{l}\text { Annualized } \\
\text { Sharpe }\end{array}$} & \multicolumn{2}{|c|}{$\begin{array}{c}\% \text { of Random Portfolios } \\
\text { Beaten*** }\end{array}$} \\
\hline & Value & Prob & Value & Prob & & & $\begin{array}{c}\text { Annualized } \\
\text { Standard } \\
\text { Deviation }\end{array}$ & $\begin{array}{l}\text { Annualized } \\
\text { Sharpe }\end{array}$ \\
\hline 0.5 & 0.220 & 0.000 & -0.001 & 0.000 & 0.149 & -1.895 & $0.00 \%$ & $7.10 \%$ \\
\hline 0.6 & 0.212 & 0.000 & -0.001 & 0.000 & 0.165 & -1.446 & $0.00 \%$ & $26.30 \%$ \\
\hline 0.7 & 0.195 & 0.000 & -0.001 & 0.026 & 0.190 & -0.838 & $0.00 \%$ & $53.20 \%$ \\
\hline 0.8 & 0.173 & 0.000 & -0.001 & 0.069 & 0.225 & -0.717 & $0.00 \%$ & $52.60 \%$ \\
\hline 0.9 & 0.183 & 0.000 & -0.001 & 0.266 & 0.258 & -0.388 & $0.00 \%$ & $73.10 \%$ \\
\hline 1.0 & 0.156 & 0.000 & 0.000 & 0.714 & 0.319 & 0.293 & $0.00 \%$ & $93.70 \%$ \\
\hline 1.1 & 0.178 & 0.000 & 0.000 & 0.936 & 0.352 & 0.154 & $0.00 \%$ & $89.10 \%$ \\
\hline 1.2 & 0.193 & 0.000 & 0.000 & 0.562 & 0.380 & 0.403 & $0.00 \%$ & $95.70 \%$ \\
\hline 1.3 & 0.236 & 0.000 & 0.001 & 0.321 & 0.385 & 0.630 & $0.00 \%$ & $97.30 \%$ \\
\hline 1.4 & 0.197 & 0.000 & 0.000 & 0.604 & 0.375 & 0.376 & $0.00 \%$ & $86.70 \%$ \\
\hline 1.5 & 0.175 & 0.000 & 0.000 & 0.804 & 0.357 & 0.234 & $0.00 \%$ & $82.60 \%$ \\
\hline 1.6 & 0.126 & 0.002 & 0.000 & 0.986 & 0.355 & 0.072 & $0.00 \%$ & $69.20 \%$ \\
\hline 1.7 & 0.078 & 0.048 & 0.000 & 0.822 & 0.346 & 0.164 & $0.00 \%$ & $76.60 \%$ \\
\hline 1.8 & 0.063 & 0.107 & 0.000 & 0.592 & 0.344 & 0.310 & $0.00 \%$ & $78.80 \%$ \\
\hline 1.9 & 0.023 & 0.533 & 0.001 & 0.389 & 0.321 & 0.448 & $0.00 \%$ & $87.50 \%$ \\
\hline 2.0 & -0.009 & 0.799 & 0.001 & 0.392 & 0.295 & 0.423 & $0.00 \%$ & $81.30 \%$ \\
\hline \multicolumn{9}{|c|}{ Panel C - Multivariate Pairs Trading using a Correlation Scheme } \\
\hline \multirow[b]{2}{*}{ Value of $d$} & \multicolumn{2}{|c|}{ Beta $^{\star \star \star \star}$} & \multicolumn{2}{|c|}{$\begin{array}{l}\text { Jensen's } \\
\text { Alpha }^{* * * *}\end{array}$} & \multirow{2}{*}{$\begin{array}{c}\text { Annualized } \\
\text { Standard } \\
\text { Deviation* }\end{array}$} & \multirow{2}{*}{$\begin{array}{l}\text { Annualized } \\
\text { Sharpe }^{* *}\end{array}$} & \multicolumn{2}{|c|}{$\begin{array}{c}\% \text { of Random Portfolios } \\
\text { Beaten*** }\end{array}$} \\
\hline & Value & Prob & Value & Prob & & & $\begin{array}{c}\text { Annualized } \\
\text { Standard } \\
\text { Deviation }\end{array}$ & $\begin{array}{c}\text { Annualized } \\
\text { Sharpe }\end{array}$ \\
\hline 0.5 & 0.245 & 0.000 & -0.001 & 0.000 & 0.150 & -1.895 & $0.00 \%$ & $14.80 \%$ \\
\hline 0.6 & 0.245 & 0.000 & -0.001 & 0.000 & 0.167 & -1.556 & $0.00 \%$ & $21.60 \%$ \\
\hline 0.7 & 0.244 & 0.000 & -0.001 & 0.005 & 0.189 & -1.010 & $0.00 \%$ & $54.00 \%$ \\
\hline 0.8 & 0.243 & 0.000 & -0.001 & 0.037 & 0.222 & -0.750 & $0.00 \%$ & $59.20 \%$ \\
\hline 0.9 & 0.252 & 0.000 & -0.001 & 0.090 & 0.251 & -0.591 & $0.00 \%$ & $58.30 \%$ \\
\hline 1.0 & 0.252 & 0.000 & 0.000 & 0.523 & 0.296 & -0.119 & $0.00 \%$ & $80.80 \%$ \\
\hline 1.1 & 0.249 & 0.000 & 0.000 & 0.657 & 0.322 & -0.042 & $0.00 \%$ & $80.00 \%$ \\
\hline 1.2 & 0.256 & 0.000 & 0.000 & 0.795 & 0.348 & 0.294 & $0.00 \%$ & $89.50 \%$ \\
\hline 1.3 & 0.251 & 0.000 & 0.000 & 0.694 & 0.364 & 0.350 & $0.00 \%$ & $90.00 \%$ \\
\hline 1.4 & 0.219 & 0.000 & 0.000 & 0.602 & 0.367 & 0.393 & $0.00 \%$ & $90.90 \%$ \\
\hline 1.5 & 0.174 & 0.000 & 0.000 & 0.913 & 0.359 & 0.164 & $0.00 \%$ & $77.60 \%$ \\
\hline 1.6 & 0.152 & 0.000 & 0.000 & 0.931 & 0.361 & 0.138 & $0.00 \%$ & $82.70 \%$ \\
\hline 1.7 & 0.143 & 0.001 & 0.001 & 0.467 & 0.365 & 0.451 & $0.00 \%$ & $92.50 \%$ \\
\hline 1.8 & 0.078 & 0.052 & 0.001 & 0.260 & 0.354 & 0.614 & $0.00 \%$ & $96.80 \%$ \\
\hline 1.9 & 0.080 & 0.032 & 0.001 & 0.416 & 0.325 & 0.462 & $0.00 \%$ & $93.90 \%$ \\
\hline 2.0 & 0.088 & 0.014 & 0.001 & 0.308 & 0.316 & 0.574 & $0.00 \%$ & $94.90 \%$ \\
\hline
\end{tabular}

* The annualized standard deviation is calculated by the multiplication of the standard deviation of the return series over time with the square root of 250 . This calculation is based on constant volatility assumption. 
** The annualized sharpe is calculated by dividing the annualized return (Table 1) by the annualized standard deviation (Table 2)

*** The bootstrap method simulated 1000 random portfolios given the method describe in previous section of the paper. For each simulated portfolio, the annualized standard deviation and the annualized sharpe were calculated. The percentage in the two columns shows the number of cases beated by the strategy (percentage of random cases with lower annualized sharpe and percentage with higher annualized standard deviation).

**** The betas and alphas are obtained with a linear regression of the vector with the strategies returns over time against the returns from Ibovespa (Broad Brazilian Market Index).

Regarding the values of systematic risk (beta) at Table 2, for all panels, it's possible to see that most of them are relatively small in absolute value, but statistically significant. For Panel A, the betas are mostly negatives, meaning that the OLS method usually presents returns in the opposite direction than the overall market (in this case the Ibovespa index). Also, Panel A shows lower absolute values of beta when comparing against Panels B and C, therefore less systematic risk for the OLS method.

For Panels B and C, again is found symmetry in the results, where the betas are positive and close in value. It's also clear for all panels that as $d$ grows, the absolute value of beta decreases, which is expected since the number of trades also has a negative relation with $d$, meaning that less trades is presenting less systematic risk, which is an intuitive result. But, one should also notes that the annualized standard deviation (unsystematic risk) is not decreasing as $d$ grows. Such event will be explained next.

Looking at the value of jensen's alpha at Table 2, it's possible to see that most of them are positive, which corroborates with the profitability analysis at Table 1. But, it's important to notes that the values of alphas aren't statistically significant, meaning that the tested framework wasn't able to produce significant positive returns after filtering for market conditions. Such information should be taken into account for the conclusions of this paper.

The results from the bootstrap method serve as a way of assessing how good the values of annualized standard deviations and the annualized sharpe ratio are against pure chance. A clear information is that, independent of the value of $d$, the strategy is picking up large volatility from the data, therefore the values of annualized standard deviation aren't decreasing with the increase of the threshold parameter. This conclusion is drawed from the fact that in all simulated cases, for all panels, the strategy presented higher annualized standard deviation than all the simulated random portfolios, meaning that the proposed trading framework is peculiarly good at trading in days with high volatility. This peculiar characteristic of the strategy could be explained by the fact that the core of the trading strategy is to pick up abnormal cases and trade for the hope of a price reversion. What the results at table 2 are suggesting is that the abnormal cases are happening at high volatile days, therefore increasing the volatility of the resulting portfolio.

When looking at the results of the bootstrap method for the sharpe ratio, the values of beated random portfolios are all close to $80 \%$, meaning that the strategy, on average, presents higher relation of return and risk than a naïve approach of random trading signals. The best results on this indicator for all panels also lies between the interval $d=1.2$ to $d=2$, which is the same for the best results at Table 1. Such information contributes to the positive performance of the strategies over the data since the risk and return relationship given by the strategies are better than the expected sharpe ratio for an out-of-skill investor, therefore the positive performance is given by skill of the method, and not pure chance. 
Since the proposed method is derived from the classical pairs trading framework, a natural analysis to be pursued here is to compare the performance indicators for each case. That is done next, Table 3, where the classical pairs trading framework is compared against the multivariate version in the correlation weighting scheme.

Table 3 - Multivariate Pairs Trading (Correlation Weighting) X Classical Pairs Trading

\begin{tabular}{|c|c|c|c|c|c|c|c|c|c|c|c|c|}
\hline \multirow{3}{*}{$\begin{array}{c}\text { Value of } \\
d\end{array}$} & \multirow{2}{*}{\multicolumn{2}{|c|}{$\begin{array}{l}\text { Annualized Raw } \\
\text { Return* }\end{array}$}} & \multirow{2}{*}{\multicolumn{2}{|c|}{$\begin{array}{l}\text { Annualized } \\
\text { Standard } \\
\text { Deviation** }^{\star *}\end{array}$}} & \multirow{2}{*}{\multicolumn{2}{|c|}{$\begin{array}{c}\text { Annualized } \\
\text { Sharpe Ratio*** }\end{array}$}} & \multicolumn{6}{|c|}{$\%$ of Random Portfolios Beaten**** } \\
\hline & & & & & & & \multicolumn{2}{|c|}{$\begin{array}{c}\text { Annualized Raw } \\
\text { Return }\end{array}$} & \multicolumn{2}{|c|}{$\begin{array}{c}\text { Annualized } \\
\text { Standard } \\
\text { Deviation Return }\end{array}$} & \multicolumn{2}{|c|}{$\begin{array}{l}\text { Annualized } \\
\text { Sharpe Ratio }\end{array}$} \\
\hline & $\mathrm{PT}$ & $T$ & & IIPT & MPT & UPT & MPT & 11 & TRT & IIPT & & \\
\hline & $-28.48 \%$ & & & & & & & & & & & \\
\hline 0.6 & $-25.94 \%$ & & & & & & & & & & & \\
\hline 0.7 & -19 & & & & -1.0 & & & & & & & \\
\hline 0.8 & -16.6 & & & & -0.7 & & & & $\%$ & & & \\
\hline 0 & 11 & & & & -0.5 & & & & $\%$ & & & \\
\hline & 35 & & & & -0.1 & & & & O & & & \\
\hline & $\%$ & & & & -0. & & & & 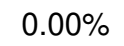 & $\%$ & & \\
\hline & $\%$ & & & & 0 & & & & 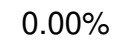 & $\%$ & & \\
\hline & & & & & 0 & & & & 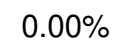 & $\%$ & & \\
\hline & & & & & & & & & .00 & & & \\
\hline & & & & & & & & & 0.0 & & & \\
\hline & & & & & & & & & 0 & & & \\
\hline & & & & & & & & & 0.0 & & & \\
\hline & & & & & & & & & & & & \\
\hline & & & & & & & & & & & & \\
\hline & & & & & & & & & & & & \\
\hline & & & & & & & & & & & & \\
\hline & & & & & & & & & & & & \\
\hline 2.3 & & & & & & & & & & & & \\
\hline 2.4 & & & & & & & & & & & & \\
\hline & & -24 & 23 & & & & & & $0.00 \%$ & & & \\
\hline 2.6 & & $-21.92 \%$ & $22.64 \%$ & & & & $100.00 \%$ & & $0.00 \%$ & & & \\
\hline & & $-12.58 \%$ & $23.40 \%$ & & & & & & $0.00 \%$ & & $89.60 \%$ & \\
\hline 2.8 & & & & & 0.470 & & & & & & & \\
\hline & & $-9.60 \%$ & $21.88 \%$ & & 7 717 & & & & $0.00 \%$ & & & \\
\hline . & $13.85 \%$ & $-10.70 \%$ & $23.98 \%$ & $24.62 \%$ & 0.578 & -0.435 & $100.00 \%$ & $0.00 \%$ & $0.00 \%$ & $0.00 \%$ & $95.60 \%$ & $37.30 \%$ \\
\hline
\end{tabular}

* The annualized raw return is calculated by taking the total raw return, divide it by the total number of days in the trading sample (in this case $997(1491$ - 494)) and then multiplying the result by 250 (average number of business days in one year).

** The annualized standard deviation is calculated by the multiplication between the standard deviation of the return series over time and the square root of 250 . This calculation is based on constant volatility assumption.

*** The annualized sharpe is calculated by dividing the annualized return by the annualized standard deviation **** The bootstrap method simulated 1000 random portfolios given the method describe in previous section of the paper. At each simulation it was calculated the raw return, standard deviation and sharpe ratio (all in annualized unit). Those 1000 values are them compared against the values from the univariate and multivariate versions of the strategy, which produced the percentages showed at this column 
For Table 3, MPT means multivariate pairs trading and UPT means univariate pairs trading. For the multivariate case, the values showed at Table 3 are for the correlation weighting scheme, which was the one with best performance over the competing methods. The values of the UPT case at Table 3 were calculated with the same algorithm as in Perlin (2006b). It should be also pointed out that Table 3 is dealing with values of $d$ between .5 and 3, which is a range higher than for the rest of the tables of the papers.

From Table 3 it's clear that the multivariate version is more profitable than the Univariate version. Such conclusion is based on the annualized returns, where the MPV case presented a higher number of positive values over the full spectrum of $d$. Such conclusion is also supported by the bootstrap method, where the MPT cases presented a higher number of percentage of beated portfolios when it comes to annualized return. This result is more explicit for high values of $d$.

When analyzing the results for the annualized standard deviation at Table 3, it's possible to see that the risk of the different strategies isn't that different from one another. The simulation of random portfolios also shows that both versions have a tendency to pick up volatility from the data, where in all cases, for the MPT and UPT, there was no simulated portfolio with volatility higher than the volatility from the trading rules. In the bootstrap method for the sharpe ratios at Table 3, it's also clear that the multivariate version presents higher ratio of expected return to risk. Such evidence is supported by the bootstrap method, where the MPT case presented a large number of beated portfolios and the UPT only presented such evidence for a smaller region of the threshold $d$. This means that the MPT version, for this particular research, delivered higher units of return per risk than the UPT version, which is a positive result towards the performance of the model.

The results obtained at this research shows that the proposed approach at pairs trading strategy presented a significant performance regarding return and risk. The values at Table 1 and 2 shows that the proposed version of the strategy performs better than a benchmark portfolio and such result is not given by chance, as one can for see for the results of the bootstrap method. When comparing against the classical pairs trading, the superiority of the performance indicators of the suggested method over the univariate case was also clear. The multivariate case delivered higher returns and higher sharpe ratios. But, not all the results were positive. For Table 2, it should be pointed out that the Jensen's alphas aren't statistically significant for the different cases, meaning that, even though the quantitative trading rules performs better than chance, it still doesn't present significant excess return after filtering for market conditions. It's important to remember that the whole analysis of Tables 1 and 2 was made with the arbitrary choice of $m=5$. The same tests showed before were conducted for values of $m$ between 2 and 10. The results for each value of $m$ are very similar to those reported here. The tables regarding this investigation are not presented in order to save space in the paper. 


\section{Conclusions}

The objective of this paper was to extend the work of Perlin (200b) by suggesting a multivariate version of the classical pairs trading strategy. The basic idea of this proposed approach is to build a pair for each stock based on information of others stocks, instead of just finding one, as was done in the univariate method. Such framework is carefully exposed and tested for the Brazilian financial market by applying the trading algorithm over the researched data. The performance of the method regarding return and risk was assessed with the execution of the trading rules to daily observations of 57 assets of the Brazilian financial market using a database from the period of 2000 to 2006.

Using three versions of a linear framework in the multivariate approach, the main evidence of this paper is that the trading rules from the multivariate pairs trading strategy had a respectable performance when applied to the Brazilian Equity market, especially with the use of a correlation weighting scheme. The evidence of positive excessive return was found at different values of the threshold parameter, showing consistency of the performance. For the case of risk, most of the calculated betas were statistically significant, meaning that the strategy does present systematic risk, but, at the same time, the betas coefficients were not so high in value. It was also found that the strategy is particularly good at picking up volatility from the data. When analyzing the return and risk relationship (sharpe ratio) the strategies still performed better than chance, meaning that the rules provided high volatility in the return vector, but this is compensated by high raw returns over time.

The results found at this study motivates the application of such quantitative formulation to other financial markets in order to check if such positive results can be replicated in a different database. It should be pointed out that the method used here can be shaped in many different ways in order to accommodate more complex models. For instance, instead of using thresholds (parameter $d$ ), one can use markov switching models in order to capture an "abnormal" state at the normalized distance vectors. The use of kalman filter also seems to be a promising research path for modeling the time varying weights of the artificial pairs. Those are interesting paths for future research.

\section{References}

ALEXANDER, C., DIMITRIU, A (2000) 'The Cointegration Alpha: Enhanced Index Tracking and Long-Short Market Strategies' ICMA Discussion Paper in Finance.

ALMEIDA, N., M., PEREIRA, P., V. (2000) 'Mudança de regime para séries financeiras: Um estudo empírico destes modelos para a realização de regras de mercado' Finance Lab Working Paper, n. 03.

BROOKS, C., KATSARIS, A., PERSAND, G. (2005) 'Timing is Everything: A Comparison and Evaluation of Market Timing Strategies' Working Paper, Available at SSRN: http://ssrn.com/abstract=834485.

CARVALHAL DA SILVA, A. L., RIBEIRO, T. L. (2002) 'Estimating and Forecasting Latin American Indexes Using Artificial Neural Networks' Proceedings of BALAS. 
CHEN, A., LEUNG, M. T., DAOUK, H. (2003) 'Application of Neural Networks to an Emerging Financial Market: Forecasting and Trading the Taiwan Stock Index' Computers \& Operations Research, v. 30, p. 901-923.

DIMSON, E., MUSSAVIAN, M. (1998) 'A brief history of market efficiency' European Financial Management, v. 4, p. 91-193.

DUEKER, M. J., NEELY, C. J. (2006) 'Can Markov Switching Models Predict Excess Foreign Exchange Returns?' Working Paper, Federal Reserve Bank of St. Louis.

EFETKHARI, B. (1997) 'The Markov Regime Switching model as Trading Tool' Working Paper, University of Cambridge.

FAMA, E. (1991) 'Efficient Capital Markets: II’ Journal of Finance, v. 46, p. 1575-1617.

FAMA, E., FRENCH, K. (1992) 'The cross-section of expected stock returns' Journal of Finance, v. 47 (2), p. 427-465.

FERNÁNDEZ-RODRÍGUEZ, F., RIVERO, S. S., FELIX, J. A. (2002) 'Nearest Neighbor Predictions in Foreign Exchange Markets' Working Paper, n. 05, FEDEA.

FERNÁNDEZ-RODRÍGUEZ, F., SOSVILLA-RIVERO, S., GARCÍA-ARTILES, M. (1997) 'Using nearest neighbor predictors to forecast the Spanish Stock Market' Investigaciones Económicas, v. 21, p. 75-91.

FERNÁNDEZ-RODRÍGUEZ, F., SOSVILLA-RIVERO, S., GARCÍA-ARTILES, M. (2001) 'An empirical evaluation of non-linear trading rules' Working paper, n. 16, FEDEA.

FRENCH, K. (1980) 'Stock Returns and the Weekend Effect' Journal of Financial Economics, March, p. 55-69.

GATEV, E., GOETZMANN, W. N., ROUWENHORST, K. G. (1999) 'Pairs Trading: Performance of a Relative Value Arbitrage Rule' Working Paper, Yale School of Management. Available at SSRN: http://ssrn.com/abstract=141615.

MADDALA, G. S. (2001) 'Introduction to Econometrics' John Wiley \& Sons.

MURPHY, J. (2001) 'Technical Analysis of the Financial Markets'. New York Institute of Finance.

PARK, C., IRWIN. (2004) 'The Profitability of Technical Analysis: A Review'. AgMAS Project Research Report, n 04.

PERLIN, M S. (2006b) Evaluation of Pairs Trading Strategy at Brazilian Financial Market, Working Paper, http://ssrn.com/abstract=952242.

PERLIN, M. S. (2006a) 'Non Parametric Modelling in Major Latin America Market Indexes: An Analysis of the Performance from the Nearest Neighbor Algorithm in Trading Strategies'. BALAS Conference, Lima, Peru.

VIDYAMURTHY, G. (2004) 'Pairs Trading: Quantitative Methods and Analysis' John Wiley \& Sons, 2004.

NATH, P. (2003) 'High Frequency Pairs Trading with U.S. Treasury Securities: Risks and Rewards for Hedge Funds', Working Paper, London Business School. 
GATEV, E., GOETZMANN, W. N., ROUWENHORST, K. G. (1999) 'Pairs Trading: Performance of a Relative Value Arbitrage Rule', Working Paper, Yale School of Management. Available at SSRN: http://ssrn.com/abstract=141615. 